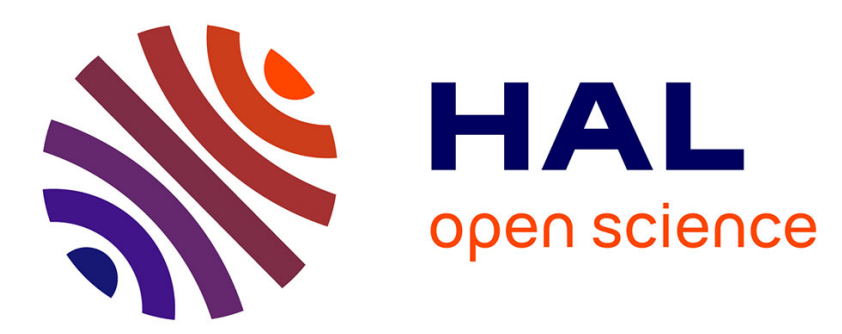

\title{
Estimating the number of alcohol-attributable deaths: methodological issues and illustration with French data for 2006.
}

Grégoire Rey, Mathieu Boniol, Eric Jougla

\section{To cite this version:}

Grégoire Rey, Mathieu Boniol, Eric Jougla. Estimating the number of alcohol-attributable deaths: methodological issues and illustration with French data for 2006.. Addiction, 2010, 105 (6), pp.1018-29. 10.1111/j.1360-0443.2010.02910.x . inserm-00844666

\section{HAL Id: inserm-00844666 https://www.hal.inserm.fr/inserm-00844666}

Submitted on 15 Jul 2013

HAL is a multi-disciplinary open access archive for the deposit and dissemination of scientific research documents, whether they are published or not. The documents may come from teaching and research institutions in France or abroad, or from public or private research centers.
L'archive ouverte pluridisciplinaire HAL, est destinée au dépôt et à la diffusion de documents scientifiques de niveau recherche, publiés ou non, émanant des établissements d'enseignement et de recherche français ou étrangers, des laboratoires publics ou privés. 


\section{Estimating the number of alcohol-attributable deaths: methodological issues and illustration with French 2006} data

Grégoire Rey ${ }^{1}$, Mathieu Boniol ${ }^{2}$, Eric Jougla ${ }^{1}$

${ }^{1}$ INSERM, CépiDc, Université Paris Sud 11, IFR69, Le Vésinet, France

${ }^{2}$ International Agency for Research on Cancer, Lyon, France

Correspondence to:

Grégoire Rey, 44 chemin de ronde, F-78116, Le Vésinet, France. E-mail: gregoire.rey@inserm.fr

Conflict of interest:

None

Running head:

Alcohol-attributable mortality: methods 


\section{Abstract}

\section{Aims}

Computing the number of alcohol-attributable deaths requires a series of hypotheses. Using French data for 2006, the potential biases are reviewed and the sensitivity of estimates to various hypotheses evaluated.

\section{Methods}

Self-reported alcohol consumption data were derived from large population-based surveys. The risks of occurrence of diseases associated with alcohol consumption and relative risks for all-cause mortality were obtained through literature searches. All-cause and causespecific population alcohol-attributable fractions (PAAFs) were calculated. In order to account for potential under-reporting, the impact of adjustment on sales data was tested. The 2006 mortality data were restricted to people aged between 15 and 75 years.

\section{Results}

When alcohol consumption distribution was adjusted for sales data, the estimated number of alcohol-attributable deaths, the sum of the cause-specific estimates, was 20255. Without adjustment, the estimate fell to 7158 .

Using an all-cause mortality approach, the adjusted number of alcohol-attributable deaths was 15950 , while the non-adjusted estimate was a negative number.

Other methodological issues such as computation based on risk estimates for all causes for 'all countries' or only 'European countries', also influenced the results, but to a lesser extent.

\section{Discussion}

The estimates of the number of alcohol-attributable deaths varied greatly, depending on the hypothesis used. The most realistic and evidence-based estimate seems to be obtained by adjusting the consumption data for national alcohol sales, and by summing the causespecific estimates. However, interpretation of the estimates must be cautious in view of their potentially large imprecision. 


\section{Introduction}

In many countries, alcohol drinking is a major public health issue. As is the case for estimation of the impact of tobacco smoking on a population (1), the number of alcoholattributable deaths has been used to evaluate the health burden of alcohol (2-9). Some studies have specifically focused on cancer attributable to alcohol (10).

Most of the recent evaluations of the dose-response relationship between alcohol consumption and cancer suggest a quasi-linear association $(11,12)$. However, a nonmonotonous J-shaped association was evidenced for coronary heart disease and stroke (1315), diabetes (16) and all-cause mortality $(17,18)$, with a lower risk for low alcohol consumption, compared to abstinence. Due to methodological concerns about the definition of abstainers $(19,20)$, the exact J-shaped relationship is still under debate $(21)$. Thus, some studies, including a Swedish study (8), pointed to a negative impact of alcohol consumption on mortality.

The method used by the various authors to calculate the proportion of alcohol-attributable deaths is simple and homogeneous, and based on the availability of relative risks determined by large meta-analyses and alcohol consumption prevalence data derived from populationbased surveys. The proportions were then applied to the number of deaths recorded in the national statistics. The simplicity of the calculation masks a large number of underlying hypotheses that are generally not taken into account in the estimation process.

One important hypothesis consists in the transferability of relative risks estimated from observational studies conducted on incident cases to death statistics $(11,12,14,16,22,23)$. For example, for the association between smoking and lung cancer, the relative risk may be used on either incidence or mortality data in a straightforward procedure, due to the high fatality of lung cancer. For other disease sites with higher survivals, the transfer of relative risk could be a source of biases and mask competitive risks among the various causes considered. 
Another major hypothesis concerns the measurement of alcohol consumption in surveys: self-reported consumption is usually greatly underestimated $(24,25)$. Hence, various authors have suggested using a correction factor based on alcohol sales data $(5,24,26)$. However, this adjustment may be misleading and give rise to a different consumption scale (reported vs. sold consumption) for relative risk estimates and population alcohol consumption incidence (27). The impact of the correction has rarely been evaluated (24).

The objective of this paper is to describe and test the impact of the various hypotheses underlying the computation of attributable fractions on the estimates of the number of alcohol-attributable deaths. French data have been used to illustrate the methodological issues and evaluate the number of alcohol-attributable deaths in France in 2006, by gender and by cause of death. 


\section{Methods}

\section{Population Alcohol-Attributable Fraction (PAAF)}

Levin's formula (28), generalized for multiple categories (n) of risk, was applied:

$$
\text { PAAF }=\frac{\sum_{i=1}^{n} P_{i} \cdot\left(R R_{i}-1\right)}{1+\sum_{i=1}^{n} P_{i} \cdot\left(R R_{i}-1\right)},
$$

in which $R_{i}$ and $P_{i}$ are the relative risks and prevalence for the $i^{\text {th }}$ category of alcohol consumption.

Variances of the PAAF were estimated by the delta method (29), with relative risk variance considered to be log-normally distributed and prevalence of alcohol consumption to be binomially distributed.

The main methodological problem relative to this widely employed formula resides in the choice of $R R_{i}$ (diseases and relative risks) and $P_{i}$ (consumption data).

Among the methodological problems related to the relative risks, the choice between a cause-specific approach and an all-cause approach was considered. As a sensitivity analysis, the all-cause results obtained by considering the 'all countries' relative risk estimates and those obtained by considering the 'European countries' relative risk estimates were compared.

Among the methodological problems related to consumption data, the need to adjust the data on alcohol sales data was considered. As a sensitivity analysis, a lag time between alcohol consumption and death, and the number of consumption categories ( $n$ ) were also considered.

\section{Choice of diseases and relative risks}

Two methods of calculating the total number of alcohol-attributable deaths were compared. 
In the first method, each cause of death was analyzed separately. Only established causes of death associated with alcohol consumption were included, using the list compiled by Jürgen Rehm (30). The PAAFs were set at $100 \%$ for by-definition alcohol-attributable causes. For the other causes, cause-specific relative risks expressed as risk by category of alcohol consumption in grammes per day were used. The relative risks were obtained from recent meta-analyses $(11,12,14,16,22,23,26,31)$ (table 1). When several meta-analyses were available, the most recent estimates including the greatest number of studies were considered.

The second approach considered overall mortality and was only based on the relative risk of all-cause mortality. The analytical expression of the association between alcohol consumption and all-cause mortality was taken from the meta-analysis by Di Castelnuovo et al. (18):

$$
\log \left(R R_{c, s}\right)=\beta_{1, s} \cdot \sqrt{c}+\beta_{2, s} \cdot \sqrt{c} \cdot \log (c),
$$

in which ' $c$ ' is the consumption level, 'RR $R_{c, s}$ ' the relative risk of death for consumption level ' $c$ ' in grammes of pure alcohol per day, compared to the abstinent level, 's' sex, and ' $\beta_{1, s}$ ' and ' $\beta_{2, s}$ ' the parameters that enable estimation of a J-shaped curve.

The parameters ' $\beta_{1, s}$ ' and ' $\beta_{2, s}$ ' were chosen from the estimates generated by 'all countries' studies. In sensitivity analyses, the 'European countries' model was also considered since it is probably affected by less bias when applied to French data, but has greater variability.

\section{Alcohol consumption data}

Two large French surveys, representative of the general population, constituted the sources of the consumption data. The alcohol questionnaires in those surveys were based on the AUDIT-C questionnaire validated by WHO (32). The measurement method is of the quantityfrequency type and targets the preceding 12 months. Other surveys had been conducted in France in previous years, but using different methodologies and questionnaires. Thus, even 
though a greater lag time could have been used, doing so would have introduced uncontrolled comparability issues.

The 2002 ESPS survey (33) included 13,000 subjects aged less than 75 years. The 2005 Health Survey (34) included 29,000 subjects aged between 15 and 75 years. For each subject, alcohol consumption expressed in grammes of pure alcohol per day was deduced from the number of drinks per day. One drink was considered to contain $10 \mathrm{~g}$ of pure alcohol. The abstainer category was defined as subjects that had not drunk any alcohol at all in the preceding year. According to the 2005 Health survey, about $40 \%$ of last-year abstainers were lifetime abstainers. It was not possible to separate former heavy drinkers from very occasional drinkers (less than once per year) in that group with our data.

\section{Adjusted vs. non-adjusted consumption data}

As expected, in both surveys, there was a marked discrepancy between the reported average consumption (about $6.2 \mathrm{~g} / \mathrm{day}$ ) and the average calculated from the French alcohol sales statistics reported to the tax authorities (30.0 g/day in 2002).

As described in previous studies $(5,24)$, for a subject ' $j$ ', adjusted alcohol consumption $\left(C_{j}^{\text {adj }}\right)$ was calculated as follows:

$C_{j}^{\text {adj }}=C_{j} \cdot \frac{S}{\bar{C}}$, in which $C_{j}$ is the consumption for a subject $j$ calculated from the general population survey, $\overline{\mathrm{C}}$ is the mean consumption calculated from the general population survey and $S$ is the mean consumption calculated from the sales data. The impact of so doing on the PAAF was investigated subsequently.

\section{Alcohol prevalence and relative risks}

The logarithms of the relative risk estimates were linearly interpolated in order to fit the consumption categories. 


\section{Lag time between adjusted consumption data and mortality}

The survey conducted in 2002 enabled a lag time of 4 years for chronic disease and for allcause mortality. Data from the 2005 survey enabled a minimal lag time for causes of death immediately related to recent alcohol consumption, such as violent death, to be considered. For chronic disease, it is likely that the alcohol related deaths from 2006 are attributable to older consumptions than those reported in the study. Given that alcohol consumption in France has been falling for 20 years (from $36.9 \mathrm{~g} /$ day in 1986 to $27.9 \mathrm{~g} /$ day in 2006), it may lead to underestimation of the related PAAFs. A sensitivity analysis thus estimated the impact of using a 20-year lag between alcohol consumption based on sales data and deaths due to chronic diseases.

\section{Choice of the number of consumption categories ( $n$ )}

If the association between the risk of death and alcohol consumption is considered to be linear, then, for all consumption categories i:

$R R_{i}=\beta \cdot \bar{C}_{i}$, in which $\bar{C}_{i}$ is the mean consumption for the $i^{\text {th }}$ category and $\beta$ the linear association.

Substituting for $\mathrm{RR}_{\mathrm{i}}$ in the PAAF formula gives:

PAAF $=\frac{\beta \cdot \sum_{i=1}^{n} P_{i} \cdot \bar{C}_{i}-1}{\beta \cdot \sum_{i=1}^{n} P_{i} \cdot \bar{C}_{i}}=\frac{\beta \cdot \bar{C}-1}{\beta \cdot \bar{C}}$, in which $\bar{C}$ is the mean overall consumption.

In consequence, for the linear association, the estimated PAAF is independent of the number of consumption categories.

However, for all-cause mortality, stroke, coronary heart disease and diabetes, the J-shaped association is far from a linear trend. Thus, the PAAF estimate is sensitive to the number of categories selected (35). As a default scenario, 6 categories were used and the impact of using 4 and 10 categories was evaluated.

\section{Age groups considered}


In most of the studies, the relative risks were already age-adjusted. The relative risks of the incidence of several diseases related to alcohol consumption were generally calculated for a middle-aged population, without considering potential competitive causes of deaths. The reported alcohol consumption is quasi-null for the population aged under 15 years. Thus, alcohol sales data are generally considered to represent the population aged 15 years and over.

Therefore, the main calculations presented in this study were limited to subjects aged between 15 and 75 years. In order to obtain estimates comparable to those of published studies, the overall results for all ages have also been presented.

\section{Years of Potential Life Lost (YPLL) attributable to alcohol}

The YPLL was defined as the remaining life expectancy at the age of death (36).

For a given disease, the number of alcohol-attributable deaths and number of alcoholattributable YPLL were calculated as the product of the PAAF and the total number of deaths and the total number of YPLL, respectively.

In the cause-specific approach, the total death PAAF was calculated as the sum of causespecific alcohol-attributable deaths divided by the all-cause number of deaths. The total YPLL PAAF was calculated in the same manner. 


\section{Results}

\section{Alcohol consumption}

The prevalence of low alcohol intakes, less than $20 \mathrm{~g} /$ day, was very high for both genders in the non-adjusted data of the ESPS 2002 survey (figure 1). Abstinence was more prevalent among women.

When the ESPS 2002 survey data were adjusted for 2002 consumption, equivalent to multiplying all the consumptions by almost 5 , the distribution extended further right (figure 1 ). Very similar alcohol distributions were observed in the 2005 Health survey.

\section{Cause-specific approach}

Population Alcohol-Attributable Fractions (PAAFs)

Cause-specific PAAFs were strongly dependent on adjustment or non-adjustment for alcohol sales data (table 2).

When adjusted for 2002 alcohol sales data, the PAAFs were generally positive, except for diabetes and ischaemic heart disease for women. However, many PAAF were not significantly different from zero (at the $5 \%$ level): ischaemic stroke and injuries and adverse effects for both genders; diabetes, haemorrhagic stroke and other chronic liver diseases for men only. In contrast, all the PAAFs were significantly positive for cancer.

The non-adjusted PAAFs were lower than the adjusted PAAFs, except for ischaemic heart diseases for women. For cancer, the non-adjusted PAAFs were all positive, but not always statistically different from 0 . For diabetes and ischaemic heart disease in both genders and ischaemic stroke for women, the PAAFs were negative.

When the consumption data were adjusted for the 1986 rather than the 2002 alcohol sales data, the PAAFs were slightly higher, reflecting the higher consumption. 
Setting the number of consumption categories to 4 or 10 instead or 6 did not change the main results.

The breakdown of the PAAF by consumption-category for the non-adjusted data revealed that the protective effect of alcohol with regard to stroke was mainly observed for the first consumption category ( $<20 \mathrm{~g} /$ day) (appendix, table 5). For the adjusted data, the greater part of the mortality for most of the diseases could be attributed to the highest consumption category (> $80 \mathrm{~g} /$ day) (appendix, table 6).

\section{Number of deaths and YPLL attributable to alcohol}

The total number of alcohol-attributable deaths for subjects aged between 15 and 75 years varied markedly, adjusted vs. non-adjusted data (7158 vs. 20255 deaths) (table 3). The corresponding proportion of total mortality (i.e. the total PAAF) varied from $4.0 \%$ for the nonadjusted data to $11.3 \%$ for the adjusted data. The causes that contributed most to this difference were cancer, stroke, and liver cirrhosis.

For subjects aged between 15 and 75 years, the total YPLL PAAF was similar to the total death PAAF for both genders and the adjusted and non-adjusted data. Thus, the age structures of alcohol-attributed mortality and general mortality were similar.

For all-age mortality, the difference between the adjusted and non-adjusted numbers of alcohol-attributable deaths was greater. Moreover, the non-adjusted mortality attributable to alcohol was negative for women (-995 deaths), and the adjusted alcohol-attributable mortality (33356 deaths) was much greater than the mortality in the group aged between 15 and 75 years. Mortality due to stroke, frequent in the elderly, accounted for most of the variations.

\section{All-cause approach}

When all-cause mortality was considered, adjustment of alcohol consumption data for alcohol sales appeared even more crucial than in the cause-specific approach (table 4). Non- 
adjusted alcohol-attributable mortality was strongly negative, with 23756 deaths of subjects aged between 15 and 75 years due to alcohol consumption avoided in France. The number of avoided deaths for men was higher than that for women.

In contrast and in a manner more consistent with the cause-specific results, 15950 deaths of subjects aged between 15 and 75 years, mostly men, were found to be attributable to alcohol consumption when the adjusted consumption data were considered.

For the all-age estimates, the difference between the non-adjusted and adjusted results was marked, with, respectively, 69154 deaths due to alcohol avoided versus 36843 attributed to alcohol consumption. The differences were observed for both the number of deaths and the YPLL.

When the 'European countries' parameter estimates from the meta-analysis reported by Di Castelnuovo were considered, the PAAFs were lower overall, but with far larger confidence intervals, particularly for women.

Similar results were obtained when the PAAFs were calculated using 4 or 10 consumption categories instead of 6 . 


\section{Discussion}

Under the various hypotheses, the numbers of alcohol-attributable deaths exhibited marked variation. After adjustment of the alcohol consumption distribution for sales data, the number of alcohol-attributable deaths of subjects aged between 15 and 75 years, considered to be the sum of the cause-specific numbers of deaths, was 20255 , equivalent to $11.3 \%$ of the overall mortality. Without adjustment for sales data, the number fell to 7158 , equivalent to $4.0 \%$ of the overall mortality. Using an all-cause mortality approach for subjects aged between 15 and 75 years, the consumption-adjusted number of alcohol-attributable deaths was 15950 (8.8\% of total mortality). Strikingly, the non-adjusted estimate was found to be negative: -23756 deaths $(-13.2 \%$ of total mortality)

Other methodological considerations also influenced the results, but to a lesser extent.

\section{Alcohol consumption}

The analysis was restricted to the quantity of alcohol consumed without addressing the pattern of consumption. However, for many diseases, and particularly coronary heart diseases, the relative risks are highly dependent on both mean consumption and consumption pattern (37). While some studies have tried to take the frequency of alcohol consumption or binge drinking into account in the estimation of the burden of disease attributable to alcohol (2), this study was unable to identify compatible consumption data and relative risk estimates based on strongly established meta-analyses that did not only consider mean consumption. For similar reasons, smoking prevalence, which constitute a strong synergistic factor with alcohol for some cancers (38), was not considered either.

The average consumptions derived from the 2002 ESPS and 2005 Health surveys are of the same order of magnitude as those in other studies $(3,6,7,24)$, but the coverage rate of the alcohol sales data is low compared to that of other estimates $(39,40)$. The protocols used to obtain the data are based on AUDIT-C methodology, which is used internationally to ensure 
data comparability, with a quantity-frequency questionnaire addressing the preceding 12 months.

Considerable literature addresses the various sources of bias in alcohol consumption measurement (25). The quantity-frequency method, like many others (41), has its limitations and generally underreports the true consumption. This method is relevant for evaluating habitual drinking patterns, but leads to under-reporting of infrequent heavy drinking. Specifically for France, the alcohol consumption categories given in the questionnaire may be too low. The relative norm may tend to minimize reporting. It is also to be noted that, in the two overall population surveys, the questions on alcohol consumption were located in the middle of a large questionnaire, and this may have influenced the answers.

The estimated average consumption is also influenced by the choice of the average amount of alcohol per drink. Usually, a glass of wine in French bars contains $12.5 \mathrm{cL}$ of wine, equivalent to $10 \mathrm{~g}$ of pure alcohol per drink. While wine is still the main alcoholic beverage in France (42), the same $10 \mathrm{~g}$ standard is often used as an approximation for beer (25 cL) or spirits (3 CL) (43). The same standard has been used in other European studies $(44,45)$. However, the amount of alcohol per drink can vary greatly depending on the beverage (wine, beer, spirits, etc.), country or place of consumption (home vs. public) $(44,46)$. To the authors' best knowledge, no study has evaluated the real content of drinks in France. Given the intercountry heterogeneity of the alcohol content of beverages (47), the $10 \mathrm{~g}$ conservative standard was selected.

In any event, the cultural and social representations of alcohol consumption are influenced by the context, and reporting discrepancies between countries, genders, age groups and geographic areas (urban vs. rural, etc.) may be observed (48).

\section{Cause-specific vs. all-cause approach}

The adoption of a cause-specific approach or an all-cause approach has great impact on the estimates. The cause-specific structure of alcohol-attributable mortality is, in itself, informative. It also enables the various associations between cause-specific incidence and 
alcohol consumption (e.g. J-shaped association for cerebrovascular diseases and linear association for some cancers) to be taken into account.

The disease selection used in the cause-specific approach is not exhaustive. It is based on the current state of knowledge of the association between alcohol and the main causes of death. Thus, the cause-specific approach may provide greater confidence than the all-cause approach with regard to the relationship between alcohol consumption and the incidence of specific diseases considered causal: it is obviously harder to take into account the various confounding factor when considering all-cause mortality.

The association between all-cause mortality and alcohol consumption has been well documented and many major possible confounding factors have already been taken into account, without dramatically changing the results (18). The association between all-cause mortality and alcohol aggregates many conditions that have not been considered yet and are potentially associated with alcohol consumption. In addition, the all-cause mortality approach avoids the potential bias due to the application of relative risks of incidence to mortality counts.

However, the association between alcohol consumption and all-cause mortality may be influenced by the cause-specific structure of the reference (i.e. abstainer) mortality (24). Hence, contrary to the cause-specific approach, the all-cause approach assumes that the population of interest and the population from which the relative risks are derived have similar cause-specific mortality structures. In order to evaluate the potential bias this could imply on the estimation of the French PAAF, we considered the European specific estimates of the association, which included French studies (18). The estimates were then lower but of the same order of magnitude than the 'all-countries' estimates.

Therefore, even if the cause-specific approach should be preferably used, the two approaches may be considered complementary rather than mutually exclusive. The difference between the two approaches is a means of quantifying the remaining part of the association between alcohol and mortality that has not been specifically identified. 


\section{Adjusted vs. non-adjusted consumption data}

General population surveys assessing alcohol consumption distribution in the overall population largely underestimate real alcohol consumption. The same issue may be encountered in epidemiological studies evaluating the relative risks in different countries. Therefore, the impact of the choice of adjustment for alcohol sales data is strongly dependent on the comparability of alcohol consumption levels between those two sources (27).

The specific attention given to alcohol consumption in epidemiological studies may better minimize, but certainly not totally eradicate, under-reporting, as has been observed in French studies $(49,50)$. Thus, the adjustment is likely to reduce the gap between the two consumption data sources. The adjusted estimates constitute an upper limit of the 'real' value, which is closer to the values reported in previous studies in France $(4,5)$. Instead of the $100 \%$ coverage rate adjustment done in this study, an intermediate coverage rate leading to intermediate mortality estimates, could have been chosen (27).

A more rigorous option would be to also address the coverage rate issue in meta-analyses. The distortion between general population surveys and epidemiological studies could be minimized by systematically adjusting alcohol consumption on the corresponding national alcohol sales data.

The method used to adjust consumption data assumes that under-reporting is independent of the level of consumption, while not modifying the proportion of abstinence. This is a strong hypothesis. Similar proportions of abstainers were observed in this study and other French observational studies $(49,50)$. However, biases could derive from this choice. It is likely that the alcohol consumption of heavy drinkers is underestimated more than that of more moderate drinkers. The amount of pure alcohol per glass used in this study, $10 \mathrm{~g}$, may be specifically underestimated for heavy drinkers (51).

With a view to comparison, it is noteworthy that the French Ministry for Road Safety estimated the number of accidental deaths attributable to alcohol to be 861 (52). This estimate, using specific additional information, can be considered a gold standard. However, 
not all alcohol-attributable violent deaths consist in road accidents. Therefore, the nonadjusted number of alcohol-attributable violent deaths, 667 deaths for all ages, is clearly underestimated. However, it is difficult to determine whether the adjusted number, 3118 alcohol-attributable violent deaths for all ages, is overestimated. Moreover, on the basis of the meta-analysis by Corrao (22), the relative risk of violent death as a function of alcohol consumption is probably the most culture- and country-dependent of all the relative risks available. Unfortunately, no independent PAAF estimates for violent assault or other types of injury are available. Had estimates been available, they would have been used instead of the general estimation method.

\section{Lag time between adjusted consumption data and mortality}

A lag time between alcohol exposure and chronic disease mortality is taken into account in some studies $(4,5)$, but more often is not $(3,6-8,10,53,54)$. One component of the decision may reside in the short term associations between alcohol per capita and mortality for some chronic diseases in population time-series studies $(55,56)$. The results support the hypotheses of a short lag time between alcohol consumption and mortality from chronic diseases. However, as discussed in those studies, the associations are weak, and could be due to many other factors, including poor quality historical data. Specifically, for ischaemic heart disease, the population time-series method has been criticised (57). Other studies have not generated consistent results $(58,59)$. Generally, the lag time has been insufficiently documented in studies estimating relative risks. However, the sensitivity analysis in the present study only showed very slight changes in the results when time-lagged alcohol sales data were considered, despite the fall in alcohol sales in France between 1986 and 2006.

\section{The abstinence issue}

In this study, abstainers were considered to be the reference. Since many current prevention policies only focus on heavy or binge drinking, the results may not appear pertinent to policy 
makers. However, abstention can also be viewed as a public health issue, and the results show that, with some hypotheses, abstention can even have a strong impact on mortality.

The authors verified that the methodological issues addressed in this paper influenced the results in the same way when the reference group consisted in moderate drinkers and when it consisted in abstainers.

According to recent results, the choice of the definition of 'abstainer' may have a marked impact on the evaluation of the risks related to consumption category for some diseases (20). However, those recent results are still under debate and the meta-analyses lack power in that the studies included were selected in a restrictive manner. Therefore, only metaanalyses that employed a broad definition of 'abstainer' were considered in the study reported herein.

The number of deaths attributable to a common environmental factor like alcohol is to be interpreted with caution. Some studies have reported positive overall mortality attributable to alcohol $(3,4,9,24)$, while another has reported negative mortality (8).

The number of alcohol-attributable deaths varied greatly, depending on the hypothesis used. More realistic and evidence-based estimates seemed to be obtained by adjusting the consumption data for national alcohol sales, and by summing the cause-specific estimates. However, given the major influence of such results on public health decisions, it appears necessary to elucidate the question of the comparability of alcohol consumption data generated by general population surveys and epidemiological studies, and that of the gap between all-cause mortality and cause-specific incidence associations with alcohol consumption.

\section{Acknowledgements}

We would like to express our gratitude to the institutions that afforded us various forms of assistance in this study: INPES, IRDES and OFDT, and to the members of those institutions 
with whom we worked: Juliette Guillemont and Arnaud Gautier with INPES; Laure ComRuelle, Thierry Rochereau and Frédérique Ruchon with IRDES; Christian Ben Lakhdar with OFDT. We also are very grateful to A. Mullarky for his skilful assistance in the preparation of the English version of this manuscript. 


\section{References}

1. Peto R, Lopez AD, Boreham J, Thun M, Heath C, Jr. Mortality from tobacco in developed countries: indirect estimation from national vital statistics. Lancet 1992;339(8804):1268-78.

2. Rehm J, Room R, Monteiro M, Gmel G, Graham K, Rehn N, et al. Alcohol use. In: Ezzati M, Lopez A, Rodgers A, Murray CJL, editors. Comparative quantification of health risks. Global and regional burden of disease attributable to selected major risk factors. Geneva: World Health Organisation; 2004. p. 959-1108.

3. Schneider M, Norman R, Parry C, Bradshaw D, Pluddemann A. Estimating the burden of disease attributable to alcohol use in South Africa in 2000. S Afr Med J 2007;97(8 Pt 2):664-72.

4. Pignon JP, Hill C. [Estimation of alcohol-related deaths in France in 1985]. Gastroenterol Clin Biol 1991;15(1):51-6.

5. IARC. Attributable causes of cancer in France in the year 2000. Lyon; 2007.

6. Corrao G, Rubbiati L, Zambon A, Arico S. Alcohol-attributable and alcoholpreventable mortality in Italy. A balance in 1983 and 1996. Eur J Public Health 2002;12(3):214-23.

7. Ridolfo B, Stevenson C. The quantification of drug-caused mortality and morbidity in Australia, 1998. Canberra: Australian Institute of Health and Welfare; 2001.

8. Sjogren H, Eriksson A, Brostrom G, Ahlm K. Quantification of alcohol-related mortality in Sweden. Alcohol Alcohol 2000;35(6):601-11.

9. John U, Hanke M. Tobacco- and alcohol-attributable mortality and years of potential life lost in Germany. Eur J Public Health 2003;13(3):275-7.

10. Boffetta P, Hashibe M, La Vecchia C, Zatonski W, Rehm J. The burden of cancer attributable to alcohol drinking. Int J Cancer 2006;119(4):884-7.

11. Bagnardi V, Blangiardo M, La Vecchia C, Corrao G. A meta-analysis of alcohol drinking and cancer risk. Br J Cancer 2001;85(11):1700-5.

12. Corrao G, Bagnardi V, Zambon A, La Vecchia C. A meta-analysis of alcohol consumption and the risk of 15 diseases. Prev Med 2004;38(5):613-9.

13. Rehm JT, Bondy SJ, Sempos CT, Vuong CV. Alcohol consumption and coronary heart disease morbidity and mortality. Am J Epidemiol 1997;146(6):495-501.

14. Corrao G, Rubbiati L, Bagnardi V, Zambon A, Poikolainen K. Alcohol and coronary heart disease: a meta-analysis. Addiction 2000;95(10):1505-23.

15. Gutjahr E, Gmel G, Rehm J. Relation between average alcohol consumption and disease: an overview. Eur Addict Res 2001;7(3):117-27.

16. Koppes LL, Dekker JM, Hendriks HF, Bouter LM, Heine RJ. Moderate alcohol consumption lowers the risk of type 2 diabetes: a meta-analysis of prospective observational studies. Diabetes Care 2005;28(3):719-25.

17. Gmel G, Gutjahr E, Rehm J. How stable is the risk curve between alcohol and allcause mortality and what factors influence the shape? A precision-weighted hierarchical metaanalysis. Eur J Epidemiol 2003;18(7):631-42.

18. Di Castelnuovo A, Costanzo S, Bagnardi V, Donati MB, Iacoviello L, de Gaetano G. Alcohol dosing and total mortality in men and women: an updated meta-analysis of 34 prospective studies. Arch Intern Med 2006;166(22):2437-45.

19. Shaper AG, Wannamethee G, Walker M. Alcohol and mortality in British men: explaining the U-shaped curve. Lancet 1988;2(8623):1267-73. 
20. Fillmore KM, Stockwell T, Chikritzhs T, Bostrom A, Kerr W. Moderate alcohol use and reduced mortality risk: systematic error in prospective studies and new hypotheses. Ann Epidemiol 2007;17(5 Suppl):S16-23.

21. Klatsky AL, Udaltsova N. Alcohol drinking and total mortality risk. Ann Epidemiol 2007; 17:S63-S67.

22. Corrao G, Bagnardi V, Zambon A, Arico S. Exploring the dose-response relationship between alcohol consumption and the risk of several alcohol-related conditions: a metaanalysis. Addiction 1999;94(10):1551-73.

23. Reynolds K, Lewis B, Nolen JD, Kinney GL, Sathya B, He J. Alcohol consumption and risk of stroke: a meta-analysis. Jama 2003;289(5):579-88.

24. Rehm J, Patra J, Popova S. Alcohol-attributable mortality and potential years of life lost in Canada 2001: implications for prevention and policy. Addiction 2006;101(3):373-84.

25. Greenfield TK, Kerr WC. Alcohol measurement methodology in epidemiology: recent advances and opportunities. Addiction 2008;103(7):1082-99.

26. Chikritzhs T, Stockwell T, Jonas H, Stevenson C, Cooper-Stanbury M, Donath S, et al. Towards a standardised methodology for estimating alcohol-caused death, injury and illness in Australia. Aust N Z J Public Health 2002;26(5):443-50.

27. Rehm J, Klotsche J, Patra J. Comparative quantification of alcohol exposure as risk factor for global burden of disease. Int J Methods Psychiatr Res 2007;16(2):66-76.

28. Levin ML. The occurrence of lung cancer in man. Acta Unio Int Contra Cancrum 1953;9(3):531-41.

29. Oehlert GW. A Note on the Delta Method. The American Statistician 1992;46(1):27-

29.

30. Rehm J, Giesbrecht S, Popova S, Patra J, Adlaf E, Mann R. Survol des bienfaits et méfaits de la consommation d'alcool - incidence sur les politiques de orévention au Canada. Toronto: Centre de toxicomanie et de santé mentale; 2006.

31. Key J, Hodgson S, Omar RZ, Jensen TK, Thompson SG, Boobis AR, et al. Metaanalysis of studies of alcohol and breast cancer with consideration of the methodological issues. Cancer Causes Control 2006;17(6):759-70.

32. Saunders JB, Aasland OG, Babor TF, de la Fuente JR, Grant M. Development of the Alcohol Use Disorders Identification Test (AUDIT): WHO Collaborative Project on Early Detection of Persons with Harmful Alcohol Consumption--II. Addiction 1993;88(6):791-804. 33. Doussin A, Dumesnil S, Le Fur P. Enquête Santé et Protection sociale (ESPS): méthode et déroulement en 2002. Questions d'économie de la santé 2002;62:1-4.

34. Guilbert P, Gautier A, Lamoureux P. Baromètre santé 2005: premiers résultats. SaintDenis: Inpes; 2006.

35. Greenland S. Attributable fractions: bias from broad definition of exposure. Epidemiology 2001;12(5):518-20.

36. Gardner JW, Sanborn JS. Years of potential life lost (YPLL)--what does it measure? Epidemiology 1990;1(4):322-9.

37. Bagnardi V, Zatonski W, Scotti L, La Vecchia C, Corrao G. Does drinking pattern modify the effect of alcohol on the risk of coronary heart disease? Evidence from a metaanalysis. J Epidemiol Community Health 2008;62(7):615-9.

38. Roy P, Esteve J. Using relative risk models for estimating synergy between two risk factors. Stat Med 1998;17(12):1357-73.

39. Stockwell T, Donath S, Cooper-Stanbury M, Chikritzhs T, Catalano P, Mateo C. Under-reporting of alcohol consumption in household surveys: a comparison of quantityfrequency, graduated-frequency and recent recall. Addiction 2004;99(8):1024-33. 
40. Ekholm O, Strandberg-Larsen K, Christensen K, Gronbaek M. Comparison of assessment methods for self-reported alcohol consumption in health interview surveys. Eur J Clin Nutr 2008;62(2):286-91.

41. Sobell LC, Sobell MB. Alcohol consumption measures. In: NIAAA, editor. A guide for clinicians and researchers. Bethesda; 2003. p. 75-99.

42. Besson D. Boissons alcoolisées: 40 ans de baisse de consommation. Insee Première 2004;966.

43. INCa. Alcool et risque de cancers; 2007.

44. Kerr WC, Patterson D, Koenen MA, Greenfield TK. Large drinks are no mistake:

glass size, not shape, affects alcoholic beverage drink pours. Drug Alcohol Rev 2009;28(4):360-5.

45. Lemmens PH. The alcohol content of self-report and 'standard' drinks. Addiction 1994;89(5):593-601.

46. Gual A, Martos AR, Lligona A, Llopis JJ. Does the concept of a standard drink apply to viticultural societies? Alcohol Alcohol 1999;34(2):153-60.

47. Bloomfield K, Stockwell T, Gmel G, Rehn N. International comparisons of alcohol consumption. Alcohol Res Health 2003;27(1):95-109.

48. Kuntsche S, Gmel G, Knibbe RA, Kuendig H, Bloomfield K, Kramer S, et al. Gender and cultural differences in the association between family roles, social stratification, and alcohol use: a European cross-cultural analysis. Alcohol Alcohol Suppl 2006;41(1):i37-46. 49. Renaud SC, Gueguen R, Siest G, Salamon R. Wine, beer, and mortality in middleaged men from eastern France. Arch Intern Med 1999;159(16):1865-70.

50. Ruidavets JB, Bataille V, Dallongeville J, Simon C, Bingham A, Amouyel P, et al. Alcohol intake and diet in France, the prominent role of lifestyle. Eur Heart J 2004;25(13):1153-62.

51. Kaskutas LA, Graves K. An alternative to standard drinks as a measure of alcohol consumption. J Subst Abuse 2000;12(1-2):67-78.

52. La sécurité routière en France: Bilan de l'année 2006. Paris: Observatoire National Interministériel de la Sécurité Routière; 2007.

53. Alcohol-attributable deaths and years of potential life lost among American Indians and Alaska Natives--United States, 2001--2005. MMWR Morb Mortal Wkly Rep 2008;57(34):938-41.

54. Alcohol-attributable deaths and years of potential life lost--United States, 2001. MMWR Morb Mortal Wkly Rep 2004;53(37):866-70.

55. Ramstedt M. Alcohol and pancreatitis mortality at the population level: experiences from 14 western countries. Addiction 2004;99(10):1255-61.

56. Ramstedt M. Fluctuations in male ischaemic heart disease mortality in Russia 19591998: assessing the importance of alcohol. Drug Alcohol Rev 2009;28(4):390-5.

57. Gruchow HW, Rimm AA, Hoffmann RG. Alcohol consumption and ischemic heart disease mortality: are time-series correlations meaningful? Am J Epidemiol 1983;118(5):64150 .

58. Hemstrom O. Per capita alcohol consumption and ischaemic heart disease mortality. Addiction 2001;96 Suppl 1:S93-112.

59. Ramstedt M. Is alcohol good or bad for Canadian hearts? A time-series analysis of the link between alcohol consumption and IHD mortality. Drug Alcohol Rev 2006;25(4):315-20. 

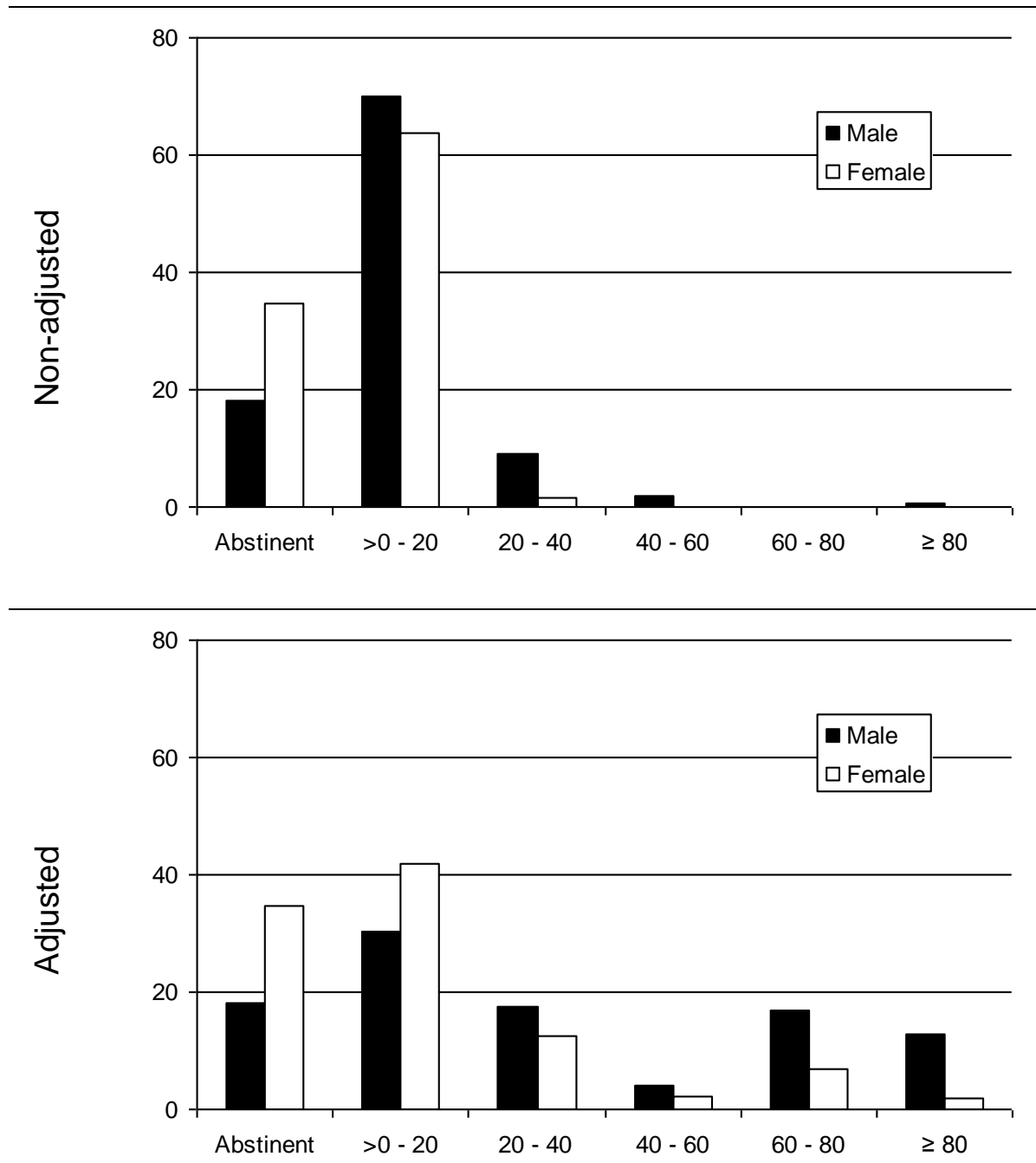

Figure 1 Prevalence of drinkers by amount of alcohol consumed in grammes of pure alcohol per day and by gender, adjusted or non-adjusted for alcohol sales data - ESPS 2002 survey 
Table 1 Relative risks of various causes of death associated with alcohol drinking expressed in grammes of pure alcohol per day.

\begin{tabular}{|c|c|c|c|c|c|c|c|}
\hline & & & & Consumption & category (grammes & f ethan & per day) \\
\hline & Conditions (ICD 10 code) & Ref. & Gender & 25 g/day & $50 \mathrm{~g} /$ day & & 0 g/ day \\
\hline & & & & RR [IC95\%] & RR [IC95\%] & & [IC95\%] \\
\hline & Oral cavity and pharynx (C01-C14) & (12) & Total & $1.86[1.76 ; 1.96]$ & $3.11[2.85 ; 3.39]$ & 6.45 & {$[5.76 ; 7.24]$} \\
\hline & Oesophagus (C15) & (12) & Total & $1.39[1.36 ; 1.42]$ & $1.93[1.85 ; 2.00]$ & 3.59 & {$[3.34 ; 3.87]$} \\
\hline & Stomach (C16) & $(11)$ & Total & $1.07[1.04 ; 1.10]$ & $1.15[1.09 ; 1.22]$ & 1.32 & {$[1.18 ; 1.49]$} \\
\hline & Colon (C18) & (12) & Total & $1.05[1.01 ; 1.09]$ & $1.1[1.03 ; 1.18]$ & 1.21 & {$[1.05 ; 1.39]$} \\
\hline 赵 & Rectum (C20) & $(12)$ & Total & $1.09[1.08 ; 1.12]$ & $1.19[1.14 ; 1.24]$ & 1.42 & {$[1.30 ; 1.55]$} \\
\hline & Liver (C22) & (12) & Total & $1.19[1.12 ; 1.27]$ & $1.4[1.25 ; 1.56]$ & 1.81 & {$[1.50 ; 2.19]$} \\
\hline & Larynx (C32) & (11) & Total & $1.38[1.32 ; 1.45]$ & $1.94[1.78 ; 2.11]$ & 3.95 & {$[3.43 ; 4.57]$} \\
\hline & Breast (C50) & (31) & Total & $1.25[1.20 ; 1.29]$ & $1.55[1.44 ; 1.67]$ & 2.41 & {$[2.07 ; 2.80]$} \\
\hline & Ovary (C56) & $(11)$ & Female & $1.11[1.00 ; 1.24]$ & $1.23[1.01 ; 1.54]$ & 1.53 & {$[1.03 ; 2.32]$} \\
\hline & Diahotor ( 51 & (16) & Male & $0.73[0.68 ; 0.80]$ & $0.91[0.80 ; 1.04]$ & 1.64 & {$[0.58 ; 4.67]$} \\
\hline & Dianctes (Liv-Lit) & (10) & Female & $0.62[0.57 ; 0.68]$ & $0.88[0.56 ; 1.41]$ & 1.41 & {$[0.21 ; 9.54]$} \\
\hline & Hypertension (I10-I15) & $(12)$ & Total & $1.43[1.33 ; 1.53]$ & $2.04[1.77 ; 2.35]$ & 4.15 & {$[3.13 ; 5.52]$} \\
\hline $\begin{array}{l}\mathbb{D} \\
\mathbb{N} \\
\mathbb{0} \\
0\end{array}$ & Ischaemic heart disease (I20-I25) & (12) & Total & $0.81 \quad[0.79 ; 0.83]$ & $0.87[0.84 ; 0.90]$ & 1.13 & {$[1.06 ; 1.21]$} \\
\hline$\frac{0}{0}$ & Haemorrhagic stroke (160-162) & 17 . & Male & $1.40[0.71 ; 2.73]$ & $2.19[1.47 ; 3.27]$ & 2.67 & {$[0.00 ;>1000]$} \\
\hline 를 & & & Female & $0.62[0.54 ; 0.71]$ & $7.98 \quad[3.25 ; 19.6]$ & 26.31 & {$[0.00 ;>1000]$} \\
\hline $\begin{array}{ll}\frac{1}{0} \\
\frac{0}{0}\end{array}$ & $663166)$ & 7 & Male & $0.99[0.85 ; 1.16]$ & $1.33[1.07 ; 1.66]$ & 2.13 & [0.02; 294.99] \\
\hline ठَّ & 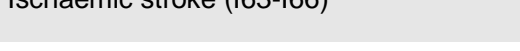 & (1) & Female & $0.61[0.54 ; 0.68]$ & $1.06[0.36 ; 3.12]$ & 2.11 & {$[0.00 ;>1000]$} \\
\hline & Liver cirrhosis $(\mathrm{K} 70, \mathrm{~K} 74.6)$ & $(12)$ & Total & $2.90[2.71 ; 3.09]$ & $7.13[6.35 ; 8.00]$ & 26.52 & [22.26; 31.59] \\
\hline & Other chronic liver diseases (K73-K74.5) & (22) & Total & $1.20[1.10 ; 1.50]$ & $1.40[1.20 ; 2.50]$ & 2.00 & {$[1.70 ; 5.70]$} \\
\hline & Chronic pancreatitis (K86.0,K86.1) & $(12)$ & Total & $1.34[1.16 ; 1.54]$ & $1.78[1.34 ; 2.36]$ & 3.19 & {$[1.82 ; 5.59]$} \\
\hline Injur & es and adverse effects (V01-Y89) & (22) & Total & $1.10[1.00 ; 1.30]$ & $1.10[1.00 ; 1.70]$ & 1.30 & {$[1.00 ; 3.10]$} \\
\hline & aus & 18, & Male & $0.91[0.89 ; 0.93]$ & $1.05[1.03 ; 1.08]$ & 1.41 & {$[1.35 ; 1.47]$} \\
\hline & & (10) & Female & $1.00[0.91 ; 1.09]$ & $1.30[1.12 ; 1.50]$ & 2.09 & {$[1.61 ; 2.70]$} \\
\hline & 烈 & 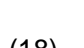 & Male & $0.80 \quad[0.72 ; 0.89]$ & $0.92[0.78 ; 1.08]$ & 1.22 & {$[0.95 ; 1.56]$} \\
\hline & & & Female & $1.07 \quad[0.55 ; 2.06]$ & $1.53[0.54 ; 4.37]$ & 2.93 & {$[0.55 ; 15.66]$} \\
\hline
\end{tabular}


Table 2 Population alcohol attributable fraction (\%) by cause and by gender, for adjusted and nonadjusted consumption data

\begin{tabular}{|c|c|c|c|c|c|c|c|c|c|}
\hline & \\
\hline & & \multicolumn{4}{|c|}{ Non-Adjusted data } & \multicolumn{4}{|c|}{ Adjusted data } \\
\hline & \multirow{2}{*}{$\begin{array}{l}\text { Condition (ICD10 code) } \\
\text { Oral cavity and pharynx (C01-C14) }\end{array}$} & \multicolumn{2}{|r|}{ Male } & \multicolumn{2}{|c|}{ Female } & \multicolumn{2}{|r|}{ Male } & \multicolumn{2}{|c|}{ Female } \\
\hline \multirow{9}{*}{ 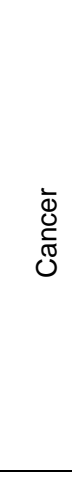 } & & 26 & {$[24 ; 28]$} & 10 & {$[8 ; 12]$} & 72 & {$[69 ; 74]$} & 38 & {$[36 ; 41]$} \\
\hline & Oesophagus (C15) & 14 & {$[12 ; 16]$} & 5 & {$[3 ; 7]$} & 54 & {$[52 ; 57]$} & 22 & {$[20 ; 25]$} \\
\hline & Stomach (C16) & 3 & {$[1 ; 5]$} & 1 & {$[-1 ; 3]$} & 13 & {$[7 ; 18]$} & 4 & {$[1 ; 6]$} \\
\hline & Colon (C18) & 2 & {$[0 ; 4]$} & 1 & {$[-1 ; 3]$} & 9 & {$[2 ; 15]$} & 3 & {$[0 ; 5]$} \\
\hline & Rectum (C20) & 3 & {$[1 ; 5]$} & 1 & {$[-1 ; 3]$} & 16 & {$[12 ; 21]$} & 5 & {$[3 ; 8]$} \\
\hline & Liver (C22) & 7 & {$[5 ; 9]$} & 2 & {$[0 ; 4]$} & 28 & {$[19 ; 35]$} & 10 & {$[7 ; 13]$} \\
\hline & Larynx (C32) & 14 & {$[12 ; 16]$} & 5 & {$[3 ; 7]$} & 58 & {$[53 ; 62]$} & 24 & {$[21 ; 26]$} \\
\hline & Breast (C50) & 9 & {$[7 ; 11]$} & 3 & {$[1 ; 5]$} & 40 & {$[33 ; 45]$} & 14 & {$[12 ; 17]$} \\
\hline & Ovary (C56) & & & 1 & {$[-1 ; 3]$} & & & 6 & {$[3 ; 10]$} \\
\hline \multirow{8}{*}{ 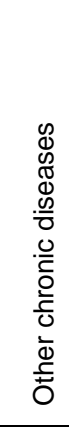 } & Diabetes (E10-E14) & -14 & {$[-22 ;-7]$} & -18 & {$[-24 ;-12]$} & 17 & {$[-3 ; 30]$} & -17 & {$[-28 ;-8]$} \\
\hline & Hypertension (I10-I15) & 15 & {$[13 ; 18]$} & 5 & {$[3 ; 7]$} & 59 & {$[49 ; 66]$} & 25 & {$[21 ; 29]$} \\
\hline & Ischaemic heart diseases (I20-125) & -5 & {$[-8 ;-3]$} & -2 & {$[-4 ; 0]$} & 2 & {$[-2 ; 6]$} & -4 & {$[-7 ; \quad-2]$} \\
\hline & Haemorrhagic stroke (160-162) & 13 & {$[9 ; 18]$} & -2 & {$[-6 ; 1]$} & 43 & {$[-100 ; 72]$} & 64 & {$[38 ; 75]$} \\
\hline & Ischaemic stroke (163-166) & 1 & {$[-2 ; 4]$} & -13 & {$[-15 ;-11]$} & 32 & {$[-83 ; 58]$} & -8 & {$[-37 ; 10]$} \\
\hline & Liver cirrhosis $(\mathrm{K} 70, \mathrm{~K} 74.6)$ & 50 & {$[47 ; 52]$} & 21 & {$[19 ; 23]$} & 92 & {$[91 ; 93]$} & 69 & {$[66 ; 72]$} \\
\hline & Other chronic liver diseases (K73-K74.5) & 7 & {$[4 ; 10]$} & 2 & {$[0 ; 4]$} & 32 & {$[-3 ; 49]$} & 11 & {$[5 ; 16]$} \\
\hline & Chronic pancreatitis (K86.0,K86.1) & 12 & {$[9 ; 15]$} & 4 & {$[2 ; 6]$} & 50 & [23; 63] & 20 & {$[13 ; 25]$} \\
\hline \multicolumn{2}{|c|}{ Injuries and adverse effects (V01-Y89) } & 2 & {$[0 ; 5]$} & 1 & {$[-1 ; 3]$} & 11 & {$[-16 ; 28]$} & 3 & {$[-1 ; 7]$} \\
\hline
\end{tabular}




\begin{tabular}{|c|c|c|c|c|c|c|c|c|c|c|c|c|c|}
\hline \multirow[b]{3}{*}{ Age } & \multirow[b]{3}{*}{ Conditions (ICD10 code) } & \multicolumn{6}{|c|}{ Not-adjusted data } & \multicolumn{6}{|c|}{ Adjusted data } \\
\hline & & \multicolumn{2}{|c|}{ Male } & \multicolumn{2}{|c|}{ Female } & \multicolumn{2}{|c|}{ Total } & \multicolumn{2}{|c|}{ Male } & \multicolumn{2}{|c|}{ Female } & \multicolumn{2}{|c|}{ Total } \\
\hline & & Deaths & YPLL & Deaths & YPLL & Deaths & YPLL & Deaths & YPLL & Deaths & YPLL & Deaths & YPLL \\
\hline \multirow{26}{*}{$\begin{array}{c}15 \\
- \\
75 \\
\text { years }\end{array}$} & Cancer & & & & & & & & & & & & \\
\hline & Oral cavity and pharynx (C01-C14) & 731 & 16461 & 45 & 1291 & 777 & 17752 & 1978 & 44541 & 174 & 4936 & 2152 & 49477 \\
\hline & Oesophagus (C15) & 299 & 6174 & 16 & 411 & 315 & 6585 & 1163 & 24034 & 76 & 1911 & 1239 & 25945 \\
\hline & Stomach (C16) & 43 & 873 & 5 & 138 & 49 & 1011 & 213 & 4313 & 25 & 634 & 238 & 4947 \\
\hline & Colon (C18) & 52 & 963 & 11 & 266 & 63 & 1229 & 253 & 4704 & 50 & 1177 & 303 & 5881 \\
\hline & Rectum (C20) & 32 & 627 & 5 & 120 & 37 & 747 & 157 & 3070 & 23 & 548 & 180 & 3618 \\
\hline & Liver (C22) & 228 & 4372 & 17 & 386 & 245 & 4758 & 928 & 17797 & 70 & 1633 & 998 & 19430 \\
\hline & Larynx (C32) & 127 & 2689 & 5 & 131 & 132 & 2820 & 521 & 10994 & 25 & 655 & 546 & 11649 \\
\hline & Breast (C50) & 9 & 172 & 203 & 5576 & 211 & 5748 & 37 & 751 & 938 & 25758 & 975 & 26510 \\
\hline & Ovary (C56) & & & 25 & 615 & 25 & 615 & & & 115 & 2824 & 115 & 2824 \\
\hline & Diabetes (E10-E14) & -284 & -5433 & -212 & -4665 & -496 & -10098 & 346 & 6630 & -207 & -4557 & 139 & 2073 \\
\hline & Mental and behavioural disorders (F10) & 2226 & 60211 & 536 & 16955 & 2762 & 77166 & 2226 & 60211 & 536 & 16955 & 2762 & 77166 \\
\hline & Degeneration of nervous system (G31.2) & 64 & 1396 & 13 & 364 & 77 & 1760 & 64 & 1396 & 13 & 364 & 77 & 1760 \\
\hline & Alcoholic polyneuropathy (G62.1) & 10 & 251 & 2 & 49 & 12 & 300 & 10 & 251 & 2 & 49 & 12 & 300 \\
\hline & Hypertension (I10-I15) & 132 & 2495 & 26 & 574 & 158 & 3070 & 505 & 9569 & 126 & 2728 & 630 & 12296 \\
\hline & Ischaemic heart diseases (I20-I25) & -454 & -9191 & -47 & -1062 & -501 & -10253 & 197 & 3987 & -86 & -1923 & 111 & 2064 \\
\hline & Alcoholic cardiomyopathy (142.6) & 72 & 1753 & 10 & 318 & 82 & 2071 & 72 & 1753 & 10 & 318 & 82 & 2071 \\
\hline & Haemorrhagic stroke (160-162) & 251 & 5503 & -32 & -831 & 220 & 4672 & 794 & 17394 & 868 & 22791 & 1662 & 40185 \\
\hline & Ischaemic stroke (163-166) & 24 & 434 & -122 & -2581 & -98 & -2147 & 613 & 10892 & -79 & -1667 & 534 & 9226 \\
\hline & Alcoholic gastritis (K29.2) & 5 & 162 & 0 & 0 & 5 & 162 & 5 & 162 & 0 & 0 & 5 & 162 \\
\hline & Liver cirrhosis $(\mathrm{K} 70, \mathrm{~K} 74.6)$ & 2293 & 52990 & 370 & 10330 & 2663 & 63319 & 4254 & 98297 & 1240 & 34603 & 5494 & 132900 \\
\hline & Other chronic liver diseases (K73-K74.5) & 1 & 26 & 1 & 12 & 2 & 39 & 6 & 119 & 2 & 55 & 8 & 173 \\
\hline & Chronic pancreatitis (K86.0,K86.1) & 9 & 216 & 0 & 11 & 9 & 227 & 35 & 886 & 2 & 53 & 37 & 939 \\
\hline & Injuries and adverse effects (V01-Y89) & 367 & 12260 & 43 & 1520 & 410 & 13780 & 1772 & 59209 & 185 & 6509 & 1956 & 65718 \\
\hline & Total attributable to alcohol & 6237 & 155403 & 921 & 29929 & 7158 & 185332 & 16148 & 380962 & 4107 & 116354 & 20255 & 497316 \\
\hline & Total PAAF* & 5.1 & 5.6 & 1.6 & 1.9 & 4.0 & 4.3 & 13.3 & 13.8 & 7.0 & 7.4 & 11.3 & 11.5 \\
\hline \multirow{2}{*}{$\begin{array}{c}\text { All } \\
\text { ages }\end{array}$} & Total attributable to alcohol & 7352 & 164813 & -995 & 18923 & 6357 & 183737 & 26017 & 449550 & 7339 & 142946 & 33356 & 592496 \\
\hline & Total PAAF* & 2.7 & 4.3 & -0.4 & 0.6 & 1.2 & 2.7 & 9.6 & 11.6 & 2.9 & 4.9 & 6.3 & 8.7 \\
\hline
\end{tabular}

YPLL: Years of potential life lost, calculated for each death as the life expectancy at the age of death

*: Proportion of the total number of deaths or YPLL, respectively 
Table 4 PAAF, number of deaths and YPLL attributable to alcohol, calculated using the all-cause

\begin{tabular}{|c|c|c|c|c|c|c|c|}
\hline \multicolumn{8}{|c|}{ mortality approach } \\
\hline & & Age - Gender & & PAAF & & $\begin{array}{c}\text { Number of } \\
\text { deaths }\end{array}$ & YPLL \\
\hline \multirow{8}{*}{$\begin{array}{l}\text { 'all-countries' } \\
\text { parameter } \\
\text { estimates }\end{array}$} & \multirow{4}{*}{ Non-adjusted data } & 15 - 75 years - Male & -13.3 & {$[-16.2$} & $-10.6]$ & -16165 & -517374 \\
\hline & & 15 - 75 years - Female & -12.9 & {$[-17.1$} & $-9.0]$ & -7591 & -377860 \\
\hline & & 15 - 75 years - Total & -13.2 & {$[-15.0$} & $-11.4]$ & -23756 & -570078 \\
\hline & & All ages - Total & -13.1 & {$[-14.5$} & $-11.8]$ & -69154 & -895233 \\
\hline & \multirow{4}{*}{ Adjusted } & 15 - 75 years - Male & 12.7 & {$[9.4$} & $15.8]$ & 15422 & 350992 \\
\hline & & 15 - 75 years - Female & 0.9 & {$[-3.7$} & $5.1]$ & 529 & 14077 \\
\hline & & 15 - 75 years - Total & 8.8 & {$[6.9$} & $10.8]$ & 15950 & 365068 \\
\hline & & All ages - Total & 7.0 & {$[5.5$} & 8.5] & 36843 & 519902 \\
\hline \multirow{8}{*}{$\begin{array}{l}\text { 'European } \\
\text { countries' } \\
\text { parameter } \\
\text { estimates }\end{array}$} & \multirow{4}{*}{ Non-adjusted data } & 15 - 75 years - Male & -22.2 & {$[-27.6$} & $-17.2]$ & -26859 & -611289 \\
\hline & & 15 - 75 years - Female & -14.4 & {$[-32.3$} & $-0.7]$ & -8446 & -224946 \\
\hline & & 15 - 75 years - Total & -19.6 & {$[-24.3$} & $-14.9]$ & -35305 & -836235 \\
\hline & & All ages - Total & -18.4 & {$[-23.0$} & $-13.8]$ & -96821 & -1280061 \\
\hline & \multirow{4}{*}{ Adjusted } & 15 - 75 years - Male & 3.1 & {$[-8.9$} & 12.7] & 3765 & 85691 \\
\hline & & 15 - 75 years - Female & 7.6 & {$[-28.1$} & 27.7] & 4443 & 118348 \\
\hline & & 15 - 75 years - Total & 4.6 & {$[-3.8$} & 13.0] & 8208 & 204039 \\
\hline & & All ages - Total & 5.3 & {$[-2.5$} & 13.1] & 27717 & 341694 \\
\hline
\end{tabular}




\section{Appendix}

Table 5 PAAF breakdown by consumption category, non-adjusted data

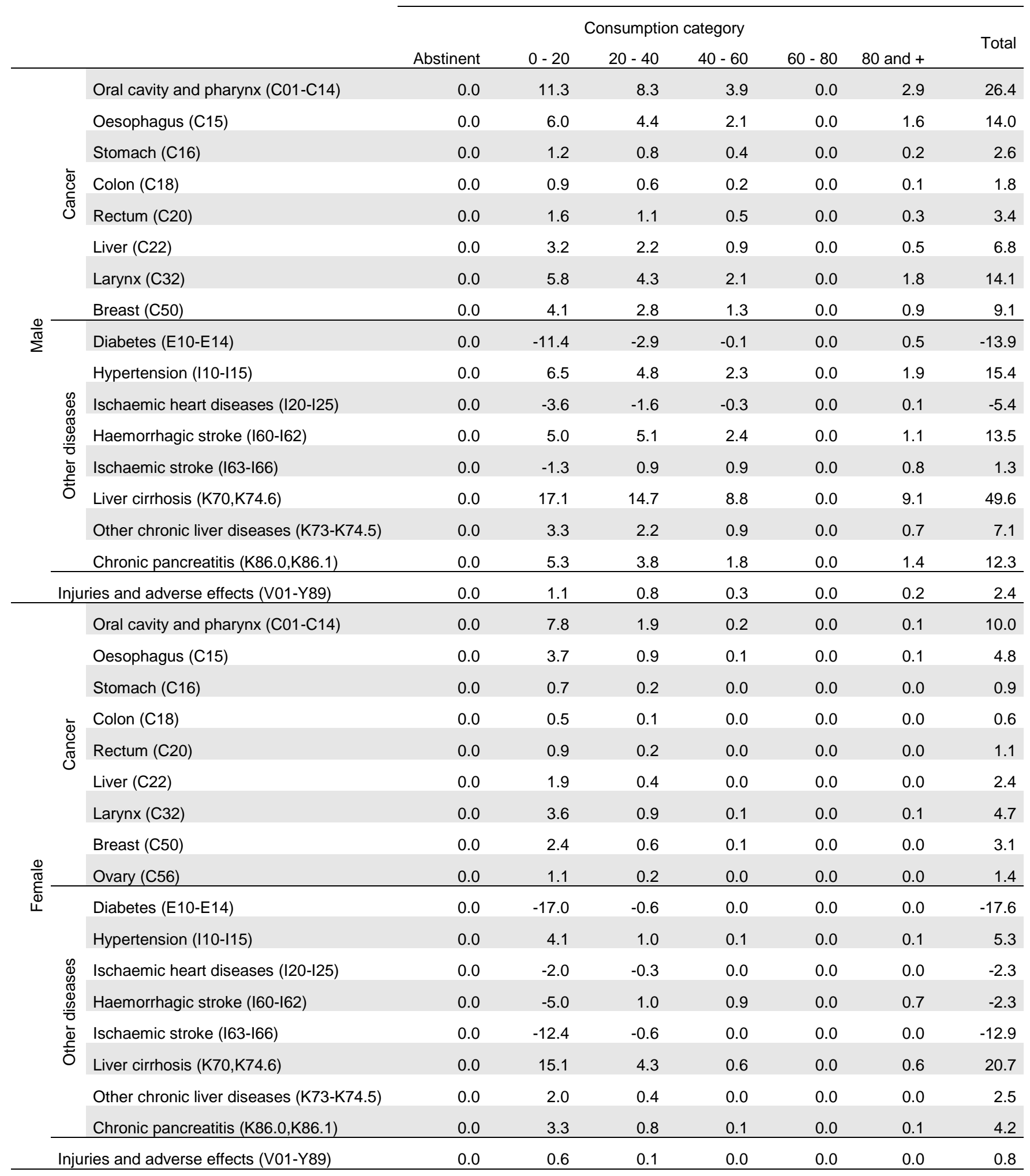




\section{Table 6 PAAF breakdown by consumption category, data adjusted for 2002 alcohol sales data}

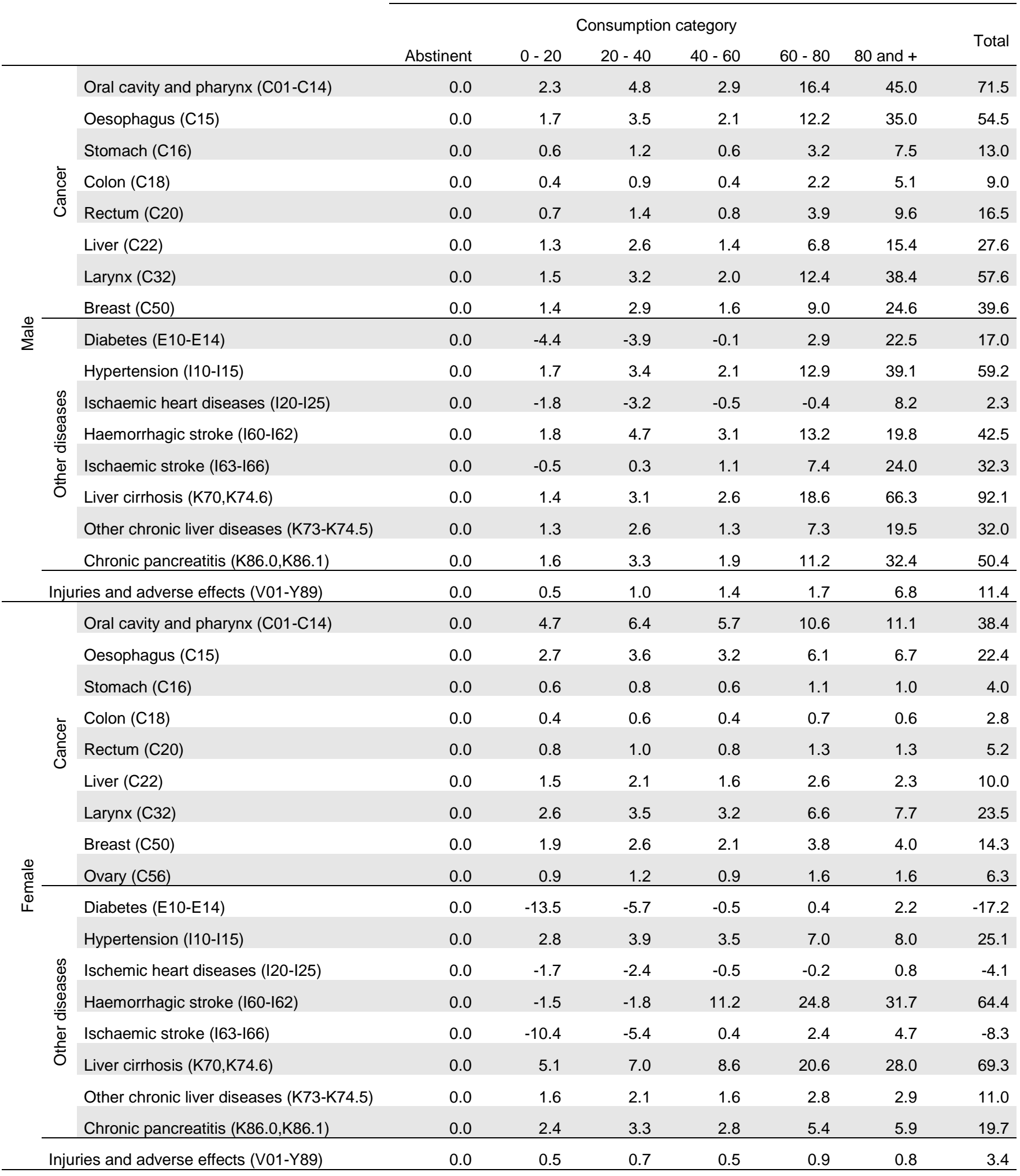

